\title{
Chronic Ethanol Ingestion Impairs Alveolar Type II Cell Glutathione Homeostasis and Function and Predisposes to Endotoxin-mediated Acute Edematous Lung Injury in Rats
}

\author{
Fernando Holguin, I. Marc Moss, Lou Ann S. Brown, and David M. Guidot \\ Atlanta VAMC and the Departments of Medicine and Pediatrics, Emory University School of Medicine, Atlanta, Georgia 30033
}

\begin{abstract}
Chronic alcohol abuse increases the incidence and mortality of the acute respiratory distress syndrome (ARDS) in septic patients. To examine a potential mechanism, we hypothesized that ethanol ingestion predisposes to sepsis-mediated acute lung injury by decreasing alveolar type II cell glutathione homeostasis and function. Lungs isolated from rats fed ethanol ( $20 \%$ in water for $\geq 3 \mathrm{wk}$ ), compared with lungs from control-fed rats, had greater $(P<0.05)$ edematous injury (reflected by nonhydrostatic weight gain) after endotoxin ( $2 \mathrm{mg} / \mathrm{kg}$ intraperitoneally) and subsequent perfusion ex vivo with $n$-formylmethionylleucylphenylalanine (fMLP, $\left.10^{-7} \mathrm{M}\right)$. Ethanol ingestion decreased $(P<0.05)$ glutathione levels in the plasma, lung tissue, and lung lavage fluid, and increased $(P<0.05)$ oxidized glutathione levels in the lung lavage fluid. Furthermore, ethanol ingestion decreased type II cell glutathione content by $95 \%(P<0.05)$, decreased $(P<0.05)$ type II cell surfactant synthesis and secretion, and decreased $(P<0.05)$ type II cell viability, in vitro. Finally, treatment with the glutathione precursors $S$-adenosyl-L-methionine and $\mathrm{N}$-acetylcysteine in the final week of ethanol ingestion significantly reduced lung edema during perfusion ex vivo. We conclude that ethanol ingestion in rats alters alveolar type II cell glutathione levels and function, thereby predisposing the lung to acute edematous injury after endotoxemia. We speculate that chronic alcohol abuse in humans predisposes to ARDS through similar mechanisms. (J. Clin. Invest. 1998. 101:761-768.) Key words: acute respiratory distress syndrome • alcohol • sepsis • surfactant $\bullet$ apoptosis
\end{abstract}

\section{Introduction}

The acute respiratory distress syndrome (ARDS) ${ }^{1}$ is a common and devastating form of acute lung injury that occurs

Address correspondence to David M. Guidot, M.D., Atlanta VAMC (151-P), 1670 Clairmont Road, Decatur, GA 30033. Phone: 404-3216111 ext. 6935; FAX: 404-728-7750; E-mail: guidot.david_m@atlanta. va.gov

Received for publication 4 August 1997 and accepted in revised form 5 December 1997.

1. Abbreviations used in this paper: ARDS, acute respiratory distress syndrome; DSPC, disaturated phosphatidylcholine; MPO, myeloperoxidase; NAC, $N$-acetylcysteine; SAM, $S$-adenosyl-L-methionine.

The Journal of Clinical Investigation

Volume 101, Number 4, February 1998, 761-768

http://www.jci.org when diverse biological insults including sepsis, trauma, and aspiration result in noncardiogenic pulmonary edema and respiratory failure, even in previously healthy people without a history of pulmonary disease. Experimental evidence indicates that multiple proinflammatory signals including endotoxin, activated complement, and cytokines initiate an inflammatory cascade that ultimately leads to diffuse alveolar damage (1). When initially described, ARDS was defined as a discrete disorder involving only the lung parenchyma (2). Based upon an improved understanding of its clinical course, ARDS is now recognized both as the severe end of a wide spectrum of acute lung injury and as the pulmonary manifestation of a systemic disorder called the multiple organ dysfunction syndrome (MODS) (3). In spite of over two and a half decades of research concerning ARDS, there is no effective therapy and the mortality remains unacceptably high at 40-60\% (4). Furthermore, as the incidence of sepsis, which is the most common risk factor for the development of ARDS, continues to rise the number of cases will also increase $(5,6)$.

In the early 1980s, two studies identified patients assumed to be at risk for the development of ARDS, and determined their actual incidence of ARDS to be $7 \%$ in one study and $34 \%$ in the other $(7,8)$. In both studies, several diverse diagnoses, such as sepsis, trauma, and aspiration of gastric contents, were prospectively identified which were associated with a higher incidence of ARDS. However, no individual diagnosis was associated with an incidence of ARDS of $>40 \%$. Therefore, other factors in addition to the specific at-risk diagnosis must play a role in determining which at-risk patients eventually develop ARDS.

Although intoxicated individuals are predisposed to several of the at-risk diagnoses, it was only recently that an epidemiological study found an association between alcohol abuse and ARDS. Researchers in Seattle reported that chronic alcohol abuse increased the risk of complications in trauma patients (9). The risk of respiratory failure, defined as respiratory distress requiring mechanical ventilation, was higher among the trauma patients with evidence of chronic alcohol abuse. Recently, a prospective study of 351 critically ill patients reported that a history of chronic alcohol abuse increased the incidence and severity of ARDS regardless of the at-risk diagnosis (10). For the entire cohort studied, the incidence of ARDS in patients with a history of chronic alcohol abuse was $43 \%$ compared with $22 \%$ in patients without a history of alcohol abuse $(P<0.001)$. For patients with sepsis as their main risk factor, a history of alcohol abuse increased the incidence of ARDS to $52 \%$ as compared with $22 \%$ in patients without a history of alcohol abuse $(P<0.001)$. Furthermore, in those patients that developed ARDS, the in-hospital mortality was higher for those with a history of chronic alcohol abuse. This observation distinguishes chronic alcohol abuse as the first reported comorbid variable that significantly increases a patient's risk of developing ARDS and raises questions about the 
pathophysiology and treatment of ARDS and the effects of alcoholism on the lung.

One potential link between chronic alcohol abuse and an increased susceptibility to acute lung injury is a derangement in glutathione homeostasis. There is considerable evidence both in animal models and in human studies that alcoholinduced hepatic injury involves glutathione depletion and consequent oxidative stress $(11,12)$. Furthermore, the lung is dependent on hepatic synthesis of glutathione because it imports glutathione from the plasma. Patients with ARDS have decreased levels of the reduced form of glutathione and increased levels of the oxidized form of glutathione in their lung lavage fluid $(13,14)$. Under normal conditions, the alveolar type II cell maintains a glutathione level in the epithelial lining fluid of $>400 \mu \mathrm{M}$, several hundred times higher than plasma and one of the highest levels identified for any extracellular fluid (15). Alveolar type II cells have diverse functions in maintaining the unique microenvironment of the alveoli, including glutathione homeostasis and surfactant secretion. They are also the progenitors of type I cells and therefore are responsible for maintaining and/or restoring the alveolar structure (16) after injury. Type II cells are sensitive to oxidative stress (17), and ARDS patients have evidence of type II cell dysfunction as reflected by low levels of surfactant $(18,19)$ in their lung lavage fluid.

Based on these observations we hypothesized that chronic alcohol abuse decreases alveolar type II cell glutathione levels and consequently impairs their surfactant production and viability, thereby predisposing critically ill patients to acute lung injury. To test this hypothesis we used an animal model of chronic ethanol ingestion in rats. We first determined that ethanol ingestion increased edematous injury in lungs isolated from endotoxin-treated rats and perfused ex vivo. We then extended these studies to examine the effects of ethanol ingestion on lung glutathione homeostasis and alveolar type II cell function.

\section{Methods}

Ethanol feeding of rats. Young adult male Sprague-Dawley rats (200$250 \mathrm{~g}$ ) were fed standard rat chow and water ad libitum. After a 1-wk acclimatization period, some rats were given ethanol $(20 \% \mathrm{vol} / \mathrm{vol}$ in their drinking water) with their standard chow while control-fed rats were maintained on standard chow and water. In each group of experiments, rats were pair-fed with either ethanol/water or water for the same period of time. In all experiments the duration of the feeding period was between 3 and $5 \mathrm{wk}$. In one group of experiments, rats were given ethanol for $2 \mathrm{wk}$ and then given the glutathione precursors $S$-adenosyl-L-methionine (SAM, $0.4 \mathrm{mg} / \mathrm{ml}$ ) and $N$-acetylcysteine $(\mathrm{NAC}, 0.163 \mathrm{mg} / \mathrm{ml}$ ) with the ethanol/water mixture for $1 \mathrm{wk}$ before lung isolation.

Isolation and perfusion of lungs. Ethanol-fed and control-fed rats were given endotoxin (Salmonella typhimurium, $2 \mathrm{mg} / \mathrm{kg}$ in saline; Sigma Chemical Co., St. Louis, MO) or saline intraperitoneally. This treatment produces acute endotoxemia and sequestration of circulating neutrophils in the pulmonary capillaries (20). After $2 \mathrm{~h}$, rats were anesthetized with pentobarbital $(60 \mathrm{mg} / \mathrm{kg}$ intraperitoneally) and a tracheostomy cannula was placed and secured with 2-O ligature. Lungs were ventilated with a tidal volume of $3 \mathrm{~cm}^{3}$ at a rate of $60 / \mathrm{min}$ with a gas mixture containing $5 \% \mathrm{CO}_{2}, 21 \% \mathrm{O}_{2}$, and $74 \% \mathrm{~N}_{2}$. After catheters were placed and secured in the pulmonary artery and left ventricle, the lungs and heart were excised en bloc, placed in an isolated lung chamber, and ventilated with $2.5 \mathrm{~cm}$ of $\mathrm{H}_{2} \mathrm{O}$ positive endexpiratory pressure added. Lungs were then perfused free of blood using Earle's balanced salt solution (Sigma Chemical Co.) to which was added sodium bicarbonate (2.2 g/liter) and Ficoll-70 $(40 \mathrm{mg} / \mathrm{ml}$; Sigma Chemical Co.), and the final $\mathrm{pH}$ adjusted to 7.40. Perfusate (30 $\mathrm{cm}^{3}$ ) was passed through the lungs to remove residual blood. The system was then closed and $30 \mathrm{~cm}^{3}$ of perfusate was continuously recirculated at a rate of $40 \mathrm{~cm}^{3} / \mathrm{kg}$ body wt $/ \mathrm{min}$. A 20-min equilibration period was followed by a 60-min experimental protocol. In some experiments, $n$-formylmethionylleucylphenylalanine (fMLP; Sigma Chemical Co.) was added at the beginning of the experimental period with a final concentration of $10^{-7} \mathrm{M}$. Pulmonary arterial pressures were monitored continuously with a pressure transducer and changes in lung weight were monitored with a force transducer. In some experiments the double vascular occlusion technique (21) was performed at the time when the mean pulmonary arterial pressures were at their maximal value in order to determine the capillary hydrostatic pressures after the addition of fMLP.

Sampling of plasma, lung tissue, and bronchoalveolar lavage fluid. Ethanol-fed and control-fed rats were anesthetized with pentobarbital $(60 \mathrm{mg} / \mathrm{kg}$ intraperitoneally), and a tracheostomy cannula was placed and secured with 2-O ligature. The lungs were ventilated with room air at 60 breaths $/ \mathrm{min}$ with a tidal volume of $3 \mathrm{~cm}^{3}$. The chest cavity was opened and heparin (100 U) was injected into the right ventricle and allowed to recirculate for $\sim 30 \mathrm{~s}$. Approximately $1 \mathrm{~cm}^{3}$ of blood was then withdrawn from the right ventricle and saved for determination of glutathione and urea levels. A perfusion catheter was then placed in the pulmonary outflow tract and, after transection of the left ventricle, the lungs were perfused blood-free with saline in order to minimize the effect of red cell glutathione on lung tissue levels. The ventilator was then disconnected and the lungs were lavaged with $5 \mathrm{~cm}^{3}$ of saline with an average recovery of $3.5 \mathrm{~cm}^{3}$. The lungs were then excised away from other tissues and frozen in liquid nitrogen for subsequent determination of glutathione levels. In some experiments, the lungs were harvested $2 \mathrm{~h}$ after treatment with endotoxin $2 \mathrm{mg} / \mathrm{kg}$ intraperitoneally for determination of myeloperoxidase (MPO) activity.

Determination of lung MPO activity. Lung MPO was determined by a modified method (22). Briefly, lungs were homogenized in $6 \mathrm{ml}$ of potassium phosphate buffer $(50 \mathrm{mM}, \mathrm{pH} 6.0)$ containing $0.5 \%$ hexadecyltrimethylammonium bromide and $5 \mathrm{mM}$ EDTA, sonicated for $30 \mathrm{~s}$, and then centrifuged at $2,300 \mathrm{~g}$ for $30 \mathrm{~min}$ at $4^{\circ} \mathrm{C} .50 \mu \mathrm{l}$ of sample was then added to $1.45 \mathrm{ml}$ of assay buffer $(100 \mathrm{mM}$ potassium phosphate, $\mathrm{pH} 6.0$, to which $83.3 \mu \mathrm{l}$ of $0.3 \% \mathrm{H}_{2} \mathrm{O}_{2} / 50 \mathrm{ml}$ and $50 \mathrm{mg}$ $o$-dianisidinehydrochloride $/ 550 \mathrm{ml}$ were added). The MPO activity in each sample was determined by measuring the change in optical density at $460 \mathrm{~nm} / \mathrm{min}$.

Determination of glutathione levels. For determining the levels of reduced glutathione in plasma, lung tissue, and freshly isolated type II cells, we used a variation of the HPLC method presented by Martin and White (23). Briefly, each sample was extracted in 5\% perchloric acid with $0.2 \mathrm{M}$ boric acid and $\gamma$-glutamyl-glutamate $(10 \mu \mathrm{M})$ as an internal standard. Iodoacetic acid was added and the $\mathrm{pH}$ was adjusted to $9.0 \pm 0.2$. After incubation for $20 \mathrm{~min}$ to obtain $S$-carboxymethyl derivatives of thiols, dansyl chloride was added and the samples were incubated for $24 \mathrm{~h}$ in the dark. Samples were then separated on an amine column with the solvents described by Reed et al. (24). Fluorescence detection was used for separation and quantification of the dansyl derivatives. The dilution of the lung epithelial lining fluid by the saline lavage was estimated by concomitant measurements of urea in the plasma and lavage fluid (25). In the lung lavage fluid samples, levels of oxidized glutathione were measured in parallel with the levels of reduced glutathione. In the plasma and lung lavage fluid, glutathione levels were expressed as a concentration (in micromolars). In the lung tissue and isolated type II cells, glutathione levels were expressed as nanomoles per milligram of protein and nanomoles per $10^{6}$ cells, respectively.

Alveolar type II cell isolation. Type II cells were isolated using a standard protocol (26). Briefly, rats were anesthetized and a tracheostomy placed followed by en bloc lung isolation. After buffer perfu- 
sion to remove intravascular blood elements, the lung airways were filled via the tracheostomy cannula with a solution containing porcine pancreatic elastase. The lung parenchyma was then cut away from the large airways and minced in a solution containing DNase and FBS (to terminate the elastase reaction). The minced lung was then successively filtered through 100 and $20 \mu \mathrm{M}$ nylon mesh and the recovered cells plated onto $100-\mathrm{mm}$ bacteriologic plastic dishes that had been coated previously with rat IgG. After a 1 -h incubation at $37^{\circ} \mathrm{C}$, the nonadherent type II cells were gently aspirated from the plates to which the alveolar macrophages and other immune cells had adhered. The type II cells were then placed in tissue culture plastic plates containing Dulbecco's modified Eagle's medium/F-12 Ham's medium (DME/F12) containing 10\% serum. Cells obtained by this method typically contain $\sim 90 \%$ alveolar type II cells that are $>90 \%$ viable by Trypan blue exclusion (26). In our study, the total number of cells isolated was quantitated and expressed as the number of adherent cells after $24 \mathrm{~h}$ in culture per lung. The type II cells were identified by staining with tannic acid and polychrome and expressed as the percentage of type II cells per the total of adherent cells after $24 \mathrm{~h}$ in culture. The viability of the type II cells after $24 \mathrm{~h}$ in culture was determined as described below.

Determination of surfactant synthesis by isolated type II cells in vitro. Freshly isolated cells were distributed onto 24-well culture plates and incubated with $0.75 \mathrm{mCi} / \mathrm{ml}$ of [methyl $-{ }^{3} \mathrm{H}$ ] choline chloride for $20 \mathrm{~h}$. After the adherence period, the wells were washed and the cells allowed to equilibrate in fresh medium without radioactivity for $30 \mathrm{~min}$ at $37^{\circ} \mathrm{C}$. In some experiments, PMA (0.01 mM) was added after the 30-min equilibration period. After $3 \mathrm{~h}$ of incubation, the medium was removed and saved. The adherent cells were extracted with $70 \%$ methanol (27). Phospholipids from both the media and the cells were then extracted with chloroform/methanol (1:1, vol/vol) and the radioactivity of the organic phase was determined. The percentage of cellular phospholipids secreted was calculated as follows: [ $\mathrm{cpm}_{\text {medium }}$ / $\left(c p m_{\text {cells }}+\right.$ cpm $\left.\left._{\text {medium }}\right)\right] \times 100 \%$. The percentage of surfactant secreted during the 30 -min equilibration period was subtracted from all samples.

To address synthesis of surfactant disaturated phosphatidylcholine (DSPC), the incorporation of $\left[{ }^{3} \mathrm{H}\right]$ choline into DSPC in freshly isolated type II cells was determined. Cells $\left(10^{6} / \mathrm{ml}\right)$ were suspended in DME/F12 (Sigma Chemical Co.) containing choline chloride $(0.05 \mathrm{mM})$, palmitic acid ( $0.1 \mathrm{mM}$, complexed with BSA), glycerol $(0.1 \mathrm{mM})$, and [methyl- ${ }^{3} \mathrm{H}$ ]choline $(1 \mathrm{mCi} / \mathrm{ml}$; sp act $80 \mathrm{Ci} / \mathrm{mmol})$ and incubated for $2 \mathrm{~h}$. Incorporation of choline into DSPC was linear over the 2 -h period. After the incubation, 0.5-ml aliquots of the cell suspension were removed and then the lipids were extracted (28). The organic layer was dried under vacuum and resuspended in chloroform/methanol (2:1). For determination of the disaturated species, the dried lipid extract was treated with osmium tetroxide in carbon tetrachloride, and the unreactive DSPC was separated by thin layer chromatography with chloroform/methanol/water (65:25:4, vol/vol/vol) (29). After identification by iodine vapor staining, the PC and DSPC bands were scraped from the chromatography plate and the radioactivity was then determined. The results are expressed as the percentage of the radioactivity in total phospholipids present in the form of DSPC.

Determination of type II cell viability in vitro. Freshly isolated type II cells were cultured as described above in DME/F12 containing $10 \%$ serum for $24 \mathrm{~h}$. The wells were washed to remove nonadherent cells. In some experiments, cell viability was determined at this step, and in other experiments $\mathrm{H}_{2} \mathrm{O}_{2}(250 \mu \mathrm{M})$ was added and the cells were incubated for $90 \mathrm{~min}$. Cell viability in untreated cells and in cells after exposure to hydrogen peroxide was determined by the fluorescent live/dead EukoLight Viability/Cytotoxicity kit (Molecular Probes, Eugene, OR). Briefly, cells were incubated with calcein AM (4 mM) and ethidium homodimer-1 (4 mM) for $30 \mathrm{~min}$. Calcein AM is a fluorogenic esterase substrate that is cleaved to yield a green fluorescent product only in viable cells with esterase activity. Ethidium homodimer-1 permeates cells with compromised membranes resulting in an orange-red fluorescence in nonviable cells. In each case, cell via- bility was expressed as the percentage of viable (green) cells among the total of [viable (green) + nonviable (orange-red) cells].

Statistical analyses. Values shown represent the mean \pm SEM. Values were compared by ANOVA and corrected by Student-Newman-Keul's test for differences between groups. $P<0.05$ was considered significant.

\section{Results}

Effects of ethanol ingestion on susceptibility to acute edematous injury during perfusion ex vivo. Lungs isolated from untreated (no endotoxin) control-fed rats and ethanol-fed rats that were perfused for $60 \mathrm{~min}$ with buffer alone (no fMLP) had no weight gain ( $n=5$ in each group; weight gains were $<0.1 \mathrm{~g}$ in each case). Lungs isolated from untreated (no endotoxin) control-fed rats and ethanol-fed rats that were perfused for 60 min with buffer and fMLP, and lungs from control-fed rats and ethanol-fed rats treated with endotoxin $(2 \mathrm{mg} / \mathrm{kg})$ and then perfused for $60 \mathrm{~min}$ with buffer alone (no fMLP) had variable but modest weight gains that did not exceed $0.5 \mathrm{~g}(n=5$ in each group). In contrast, lungs isolated $2 \mathrm{~h}$ after endotoxin treatment $(2 \mathrm{mg} / \mathrm{kg})$ from ethanol-fed rats and then perfused with fMLP $\left(10^{-7} \mathrm{M}\right)$ gained 5.4 $\pm 0.6 \mathrm{~g}$ compared with identically treated lungs isolated from control-fed rats that gained $1.5 \pm 0.1 \mathrm{~g}(P<0.05)$ (Fig. $1 A)$. By comparison however, isolated lungs from ethanol-fed rats and control-fed rats given endotoxin and perfused with fMLP had the same $(P>0.05)$ increases in mean pulmonary arterial pressures $(9.3 \pm 1.2$ vs. $8.5 \pm 2.0 \mathrm{mmHg}$; Fig. $1 B)$ and the same $(P>0.05)$ durations of pulmonary hypertension (as reflected by the time until the mean pulmonary arterial pressures returned to within $1 \mathrm{mmHg}$ of the baseline values) ( $8 \pm 4$ vs. $14 \pm 6$ min; Fig. $1 C$ ). The baseline mean pulmonary arterial pressures in all lungs were $7 \pm 1$ $\mathrm{mmHg}$. In addition, the capillary hydrostatic pressures, as determined by the double vascular occlusion technique, were all $\leq 6 \mathrm{mmHg}$, which is normal for these preparations (21), and there were was no difference $(P>0.05)$ between the groups (not shown in Fig. 1). Finally, lungs from ethanol-fed and control-fed rats treated with endotoxin had the same $(P>0.05)$ tissue levels of MPO (0.70 \pm 0.09 delta $\mathrm{Abs}_{460} / \mathrm{min}$ vs. $0.82 \pm 0.10$ delta $\mathrm{Abs}_{460} / \mathrm{min}$; Fig. $1 \mathrm{D}$; MPO levels in untreated lungs from control-fed rats were $0.13 \pm 0.02$ delta $\mathrm{Abs}_{460} / \mathrm{min}$ ).

Effects of ethanol ingestion on glutathione levels in plasma, lung tissue, and lung lavage fluid. The glutathione levels in the plasma and lung tissue from ethanol-fed rats were lower $(P<0.05)$ than in the plasma and lung tissue from control-fed rats $(2.6 \pm 0.3$ vs. $8.4 \pm 1.0 \mu \mathrm{M}$ in plasma; Fig. $2 A ; 14 \pm 2$ vs. $21 \pm 3$ $\mathrm{nmol} / \mathrm{mg}$ protein in lung tissue; Fig. $2 B$ ). In addition, the glutathione levels in the lung lavage fluid from ethanol-fed rats were lower $(P<0.05)$ than in the lung lavage fluid from controlfed rats $(107 \pm 18$ vs. $335 \pm 28 \mu \mathrm{M}$; Fig. $3 A)$. In contrast, the levels of oxidized glutathione $(G S S G)$ in the lung lavage fluid from ethanol-fed rats were higher $(P<0.05)$ than in the lung lavage fluid from control-fed rats $(8.1 \pm 2.0$ vs. $4.7 \pm 0.9 \mu \mathrm{M}$; Fig. $3 B)$.

Effects of ethanol ingestion on type II cell recovery. After $24 \mathrm{~h}$ in culture, the number of adherent cells isolated from lungs in ethanol-fed and control-fed rats were comparable $\left(20 \pm 3 \times 10^{6}\right.$ vs. $21 \pm 4 \times 10^{6}$ cells/lung). The percentage of type II cells in each group was also comparable ( $94 \pm 2$ vs. $93 \pm 2 \%)$.

Effects of ethanol ingestion on type II cell glutathione content. The glutathione content in freshly isolated type II cells from ethanol-fed rats was lower $(P<0.05)$ than the glu- 


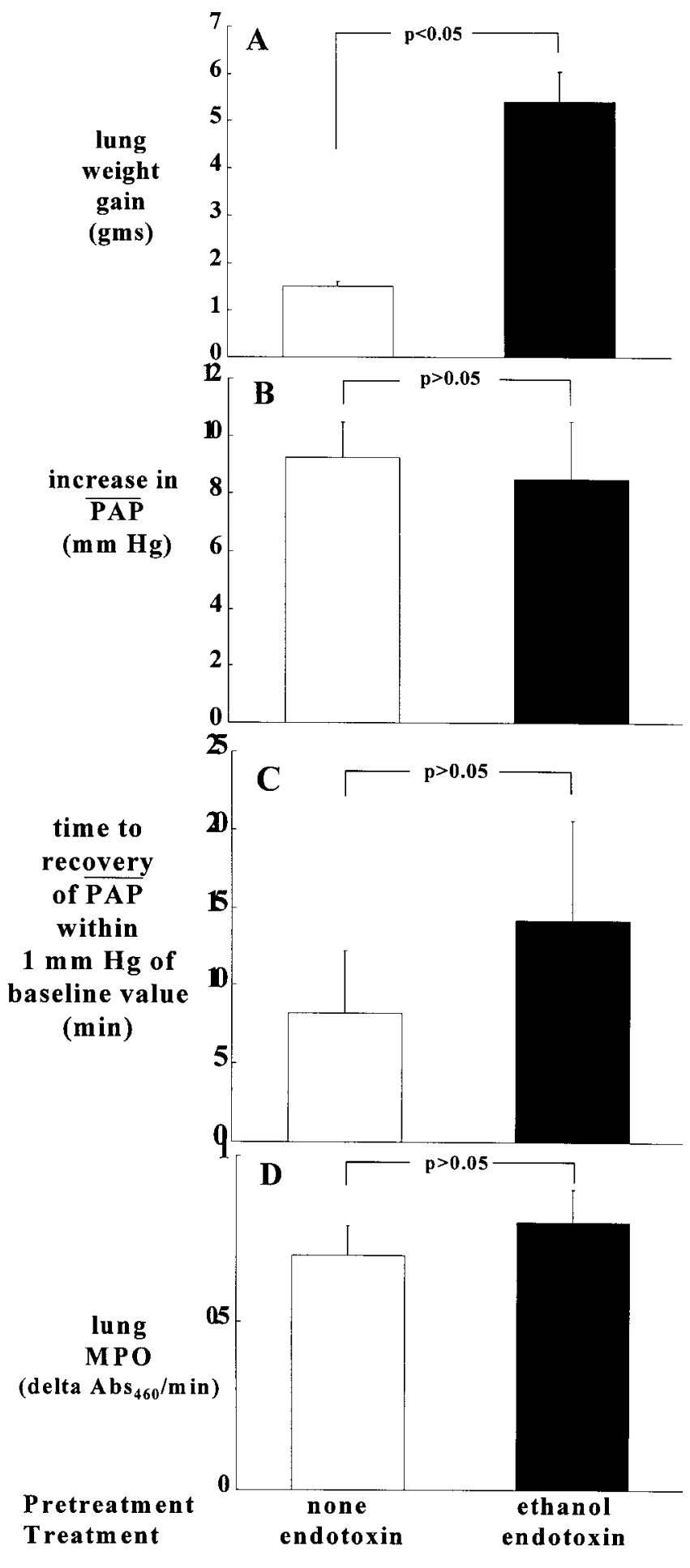

Figure 1. Weight gain $(A)$, maximal increase in mean pulmonary arterial pressure $(P A P)(B)$, duration of rise in mean PAP as reflected by time (minutes) until mean PAP returned to within $1 \mathrm{mmHg}$ of baseline value $(C)$, and lung MPO activity as reflected by delta $\mathrm{Abs}_{460} / \mathrm{min}(D)$ in lungs isolated from rats fed a standard control diet without ethanol and from rats fed a standard control diet with etha$\mathrm{nol}(20 \% \mathrm{vol} / \mathrm{vol}$ in water). Lungs were isolated $2 \mathrm{~h}$ after treatment with endotoxin ( $2 \mathrm{mg} / \mathrm{kg}$ intraperitoneally) and then perfused for $1 \mathrm{~h}$ with a Ficoll-containing salt buffer to which fMLP $\left(10^{-7} \mathrm{M}\right)$ was added. Each value represents the mean \pm SEM of five or more determinations.
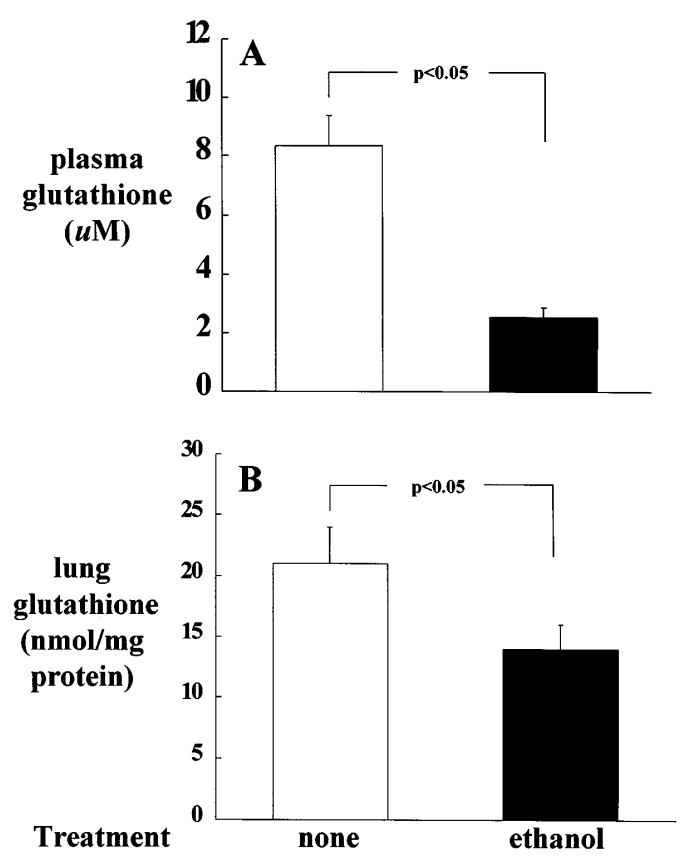

Figure 2. Glutathione levels in plasma $(A)$ and lung tissue $(B)$ in rats fed a standard control diet without ethanol and in rats fed a standard control diet with ethanol ( $20 \% \mathrm{vol} / \mathrm{vol}$ in water). Each value represents the mean \pm SEM of five or more determinations.

tathione content in freshly isolated type II cells from controlfed rats ( $5 \pm 1$ vs. $108 \pm 20 \mathrm{nmol} / 10^{6}$ cells; Fig. 4). As shown, the glutathione content in type II cells from ethanol-fed rats was $<5 \%$ of the glutathione content in type II cells from controlfed rats, representing a much greater difference than was de-

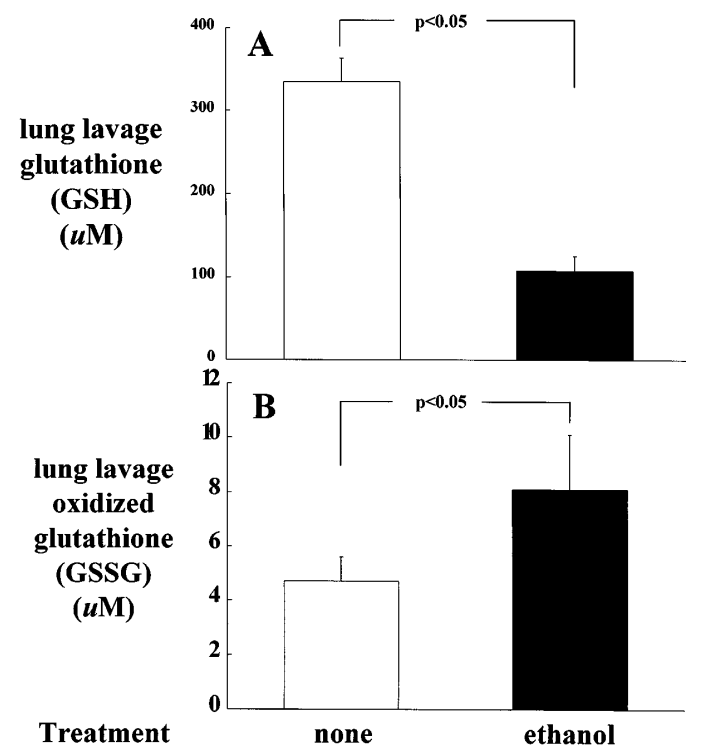

Figure 3. Lung lavage fluid levels of glutathione $(A)$ and oxidized glutathione $(G S S G)(B)$ in rats fed a standard control diet without ethanol and in rats fed a standard control diet with ethanol $(20 \% \mathrm{vol} /$ vol in water). In each sample the dilution was corrected by the urea method as described in the text. Each value represents the mean \pm SEM of five or more determinations. 


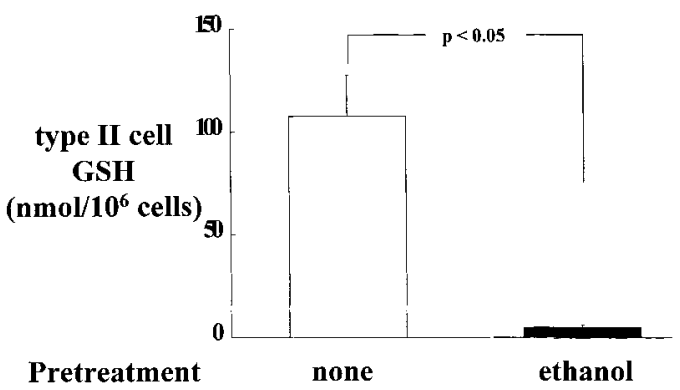

Figure 4. Levels of glutathione in type II cells isolated from rats fed a standard control diet without ethanol and from rats fed a standard control diet with ethanol ( $20 \% \mathrm{vol} / \mathrm{vol}$ in water). Each value represents the mean \pm SEM of five or more determinations.

termined in plasma or lung tissue (Fig. 2, $A$ and $B$ ) or in lung lavage fluid (Fig. $3 A$ ) between these two groups.

Effects of ethanol ingestion on type II cell surfactant synthesis and secretion in vitro. Freshly isolated type II cells from ethanol-fed rats incorporated less $(P<0.05)\left[{ }^{3} \mathrm{H}\right]$ choline into DSPC when compared with type II cells from control-fed rats $(5.3 \pm 1.6$ vs. $15.7 \pm 1.3 \%$; Fig. $5 A)$. In addition, isolated type II cells from ethanol-fed rats had lower $(P<0.05)$ basal and PMA-stimulated rates of surfactant secretion (as reflected by secretion of $\left[{ }^{3} \mathrm{H}\right] \mathrm{DSPC}$ into the medium) compared with type II cells from control-fed rats $(1.0 \pm 0.2$ vs. $2.6 \pm 0.6 \%$ basal rate and $1.4 \pm 0.2$ vs. $8.3 \pm 1.4 \%$ after PMA; Fig. $5 B$ ).

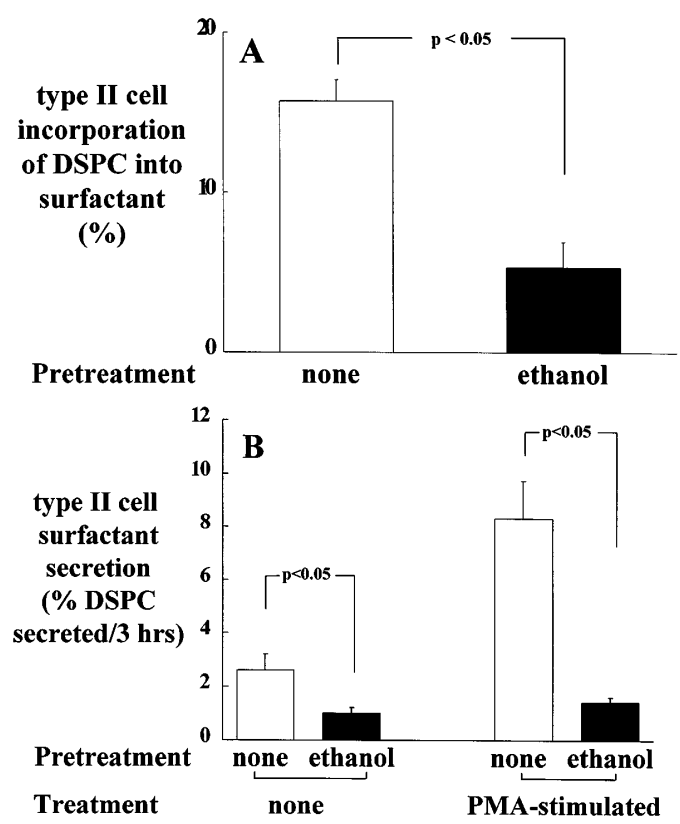

Figure 5. Surfactant synthesis and secretion by type II cells isolated from rats fed a standard control diet without ethanol and from rats fed a standard control diet with ethanol ( $20 \% \mathrm{vol} / \mathrm{vol}$ in water $)$. Shown in $A$ is the percent incorporation of $\left[{ }^{3} \mathrm{H}\right]$ choline into $\left[{ }^{3} \mathrm{H}\right] \mathrm{DSPC}$ by isolated type II cells in vitro. Shown in $B$ is the percentage of $\left[{ }^{3} \mathrm{H}\right]$ DSPC secreted by isolated type II cells in vitro over $3 \mathrm{~h}$ under basal conditions and after stimulation with PMA (0.01 mM). Each value represents the mean \pm SEM of five or more determinations.

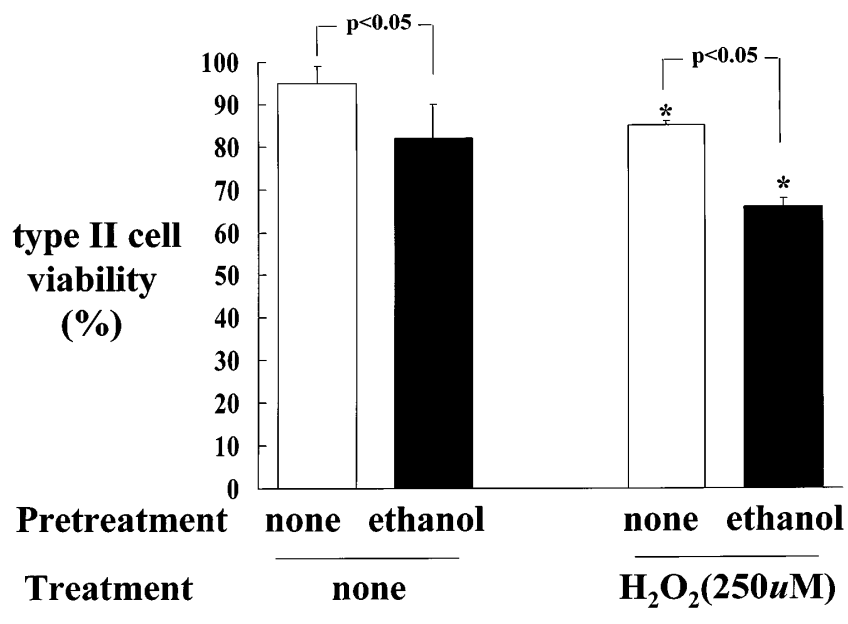

Figure 6. Viability of type II cells isolated from rats fed a standard control diet without ethanol and from rats fed a standard control diet with ethanol ( $20 \% \mathrm{vol} / \mathrm{vol}$ in water) both at baseline and $90 \mathrm{~min}$ after exposure to $\mathrm{H}_{2} \mathrm{O}_{2}(250 \mu \mathrm{M})$. Shown are the percentages of cells that have esterase activity and the ability to extrude ethidium homodimer-1 from the cytoplasm, as determined by fluorescent microscopy as described in the text. Each value represents the mean \pm SEM of five or more determinations. $* P<0.05$ compared with cells from identically fed rats but not exposed to $\mathrm{H}_{2} \mathrm{O}_{2}$.

Effects of ethanol ingestion on type II cell viability in vitro. After $24 \mathrm{~h}$ in culture, although cells from both groups were adherent to the tissue culture plastic, type II cells isolated from ethanol-fed rats were less viable $(P<0.05)$ as reflected by their esterase activity and ability to extrude ethidium homodimer-1 from the cytoplasm compared with type II cells isolated from control-fed rats ( $82 \pm 8$ vs. $95 \pm 4 \%$; Fig. 6$)$. In addition, $90 \mathrm{~min}$ after exposure to $\mathrm{H}_{2} \mathrm{O}_{2}(250 \mu \mathrm{M})$, type II cells isolated from ethanol-fed rats were even less viable $(P<0.05)$ compared with type II cells isolated from control-fed rats (66 \pm 2 vs. $85 \pm 1 \%$; Fig. 6 ).

Effect of glutathione replacement therapy with SAM and $N A C$ on susceptibility to acute edematous injury during perfusion ex vivo. Lungs isolated from ethanol-fed rats that received the glutathione precursors SAM $(0.4 \mathrm{mg} / \mathrm{ml})$ and NAC $(0.163 \mathrm{mg} / \mathrm{ml})$ for $1 \mathrm{wk}$ had less weight gain in the ex vivo perfusion model than did lungs isolated from ethanol-fed rats (3.3 \pm 1.2 vs. $5.4 \pm 0.6$ g, $P<0.05$; Fig. 7$)$, although this was greater $(P<0.05)$ than in lungs from control-fed rats (Fig. 7$)$.

\section{Discussion}

We determined that chronic ethanol ingestion in rats increased acute edematous injury in endotoxin-primed, isolated lungs perfused with fMLP. This model produces intense neutrophil sequestration in the pulmonary capillaries (20), and acute edema formation after perfusion with fMLP, a potent activator of neutrophils and other inflammatory cells. We used this model, which mimics some of the features of sepsis-mediated lung injury, in order to test our hypothesis that ethanol ingestion renders the lung susceptible to neutrophil-dependent injury as occurs in ARDS. In contrast to models of sepsis in vivo, in which innumerable systemic effects, particularly cardiac dysfunction and consequent tissue hypoperfusion, cannot be 


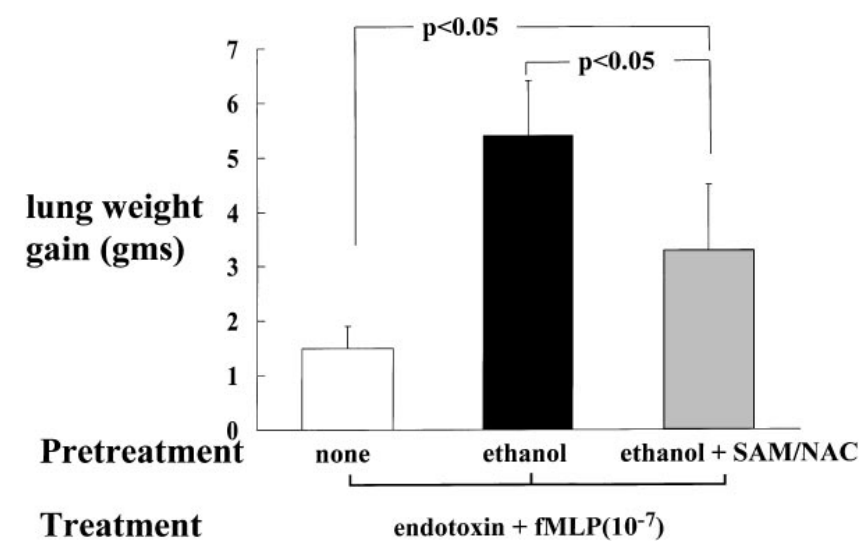

Figure 7. Weight gain in lungs isolated from control-fed rats, ethanolfed rats, and ethanol-fed rats with SAM $(0.4 \mathrm{mg} / \mathrm{ml})$ and NAC $(0.163$ $\mathrm{mg} / \mathrm{ml}$ ) added to the ethanol/water mixture for the last week of ingestion. Lungs were isolated $2 \mathrm{~h}$ after treatment with endotoxin $(2 \mathrm{mg} / \mathrm{kg}$ intraperitoneally) and then perfused for $1 \mathrm{~h}$ with a Ficoll-containing salt buffer to which fMLP $\left(10^{-7} \mathrm{M}\right)$ was added. Each value represents the mean \pm SEM of five or more determinations.

controlled, this model allows a more direct test of intrinsic lung integrity. In this model the pulmonary perfusion is fixed and there was no evidence that lungs from ethanol-fed rats retained more neutrophils or incurred greater pulmonary hypertension or capillary hydrostatic pressures during the acute perfusion than lungs from control rats. Therefore, we could not identify any evidence that lungs from ethanol-fed rats were exposed to greater inflammatory or hemodynamic stress than were lungs from control-fed rats, and our results in an ex vivo perfusion model argue that the increased edematous injury caused by ethanol ingestion cannot be ascribed to hepatic and/ or cardiac dysfunction, two well-recognized targets of ethanol toxicity. This is consistent with our previous finding that chronic alcohol abuse increases the incidence of ARDS in patients with sepsis (10). Although both alcoholics and nonalcoholics are at risk, the incidence is more than doubled in chronic alcoholics (10). Our current study suggests that ethanol ingestion alone, independent of smoking or other drug use that frequently accompanies alcohol abuse, renders the lung more susceptible to endotoxin-mediated injury.

In our model we administered ethanol in the drinking water. This method has been used in multiple other studies in rats that have examined the effects of ethanol ingestion in a variety of tissues and physiological responses (30-33). Specially formulated isocaloric liquid diets were developed in the 1960s to study the hepatotoxicity of ethanol ingestion in animal models (12). These diets were used because at the time it was unclear how much of an effect poor nutrition had in the development of cirrhosis, and there was some clinical bias that chronic alcohol abuse alone, in the absence of malnutrition, was not injurious. The consistent finding that ethanol ingestion produces similar hepatic injury regardless of the diet administered has solidified the evidence for ethanol and/or its metabolites as the cause of liver disease in chronic alcoholics. Obviously, neither an isocaloric liquid diet with ethanol nor a diet in which rats consume ethanol/water ad libitum as we used can be expected to reproduce the patterns of alcohol abuse and the sporadic dietary habits of patients with alcoholism.
To examine a possible mechanism by which ethanol ingestion could predispose the lung to endotoxin-mediated acute injury, we hypothesized that chronic alcohol abuse could affect lung glutathione homeostasis. We based this hypothesis on three prior observations. First, glutathione is a critical antioxidant in the alveolar lining fluid that is synthesized in the liver and exported via the plasma to other tissues including the lung. Second, hepatic tissue glutathione levels are decreased in chronic alcoholics whether or not there is evidence of cirrhosis (11), and in experimental animal models ethanol administration decreases glutathione synthesis and increases glutathione turnover independently of glutathione oxidation (12). Third, patients with ARDS have decreased levels of the reduced form of glutathione and increased levels of the oxidized form of glutathione in their lung lavage fluid $(13,14)$. An inadequate supply of glutathione in the lung and in type II cells in particular would render these cells vulnerable to oxidative damage and limit their ability to increase surfactant production and proliferate during lung repair. Therefore, we examined the effects of ethanol ingestion on lung glutathione homeostasis and focused in particular on the alveolar type II cell.

We determined that ethanol ingestion significantly decreased plasma levels of glutathione but only moderately decreased total lung tissue levels of glutathione. This latter finding is consistent with other studies in which ethanol ingestion had no significant effect on total lung glutathione $(34,35)$, and at first examination would appear to suggest that ethanol ingestion does not have a biologically significant effect on lung glutathione. However, we determined that lung lavage levels of glutathione were decreased to less than a third of the levels in control rats. Furthermore, lung lavage levels of oxidized glutathione were significantly increased in ethanol-fed rats compared with controls, suggesting that there is some degree of oxidative stress and/or increased turnover of glutathione in this space. However, even more dramatic was the decrease in type II cell glutathione content in ethanol-fed rats, $<5 \%$ of the levels found in type II cells from control-fed rats. Therefore, the modest decreases in total lung tissue glutathione did not reflect the magnitude of the decrease in the levels of glutathione in either the type II cell or the lung lavage fluid caused by ethanol ingestion.

In parallel to the profound decrease in type II cell glutathione levels, we also determined that ethanol ingestion significantly impaired type II cell surfactant synthesis and secretion, and decreased cell viability in vitro. Surfactant dysfunction is a hallmark of ARDS $(18,19)$, and chronic alcohol abuse could predispose to ARDS and could worsen its prognosis by impairing surfactant synthesis and secretion in vivo. In addition, type II cells isolated from ethanol-fed rats were less viable after $24 \mathrm{~h}$ in culture, and were even less viable after a 90-min exposure to hydrogen peroxide. This suggests that type II cells from alcoholic patients could be more susceptible to oxidative stress in vivo, thereby rendering these cells less able to proliferate and repair the acutely damaged alveolar epithelium during ARDS.

We have some evidence that the observed defects in surfactant production and cell viability are not merely coincidental to glutathione depletion. We determined that treatment with the glutathione precursors SAM and NAC given near the end of the period of ethanol ingestion could partially reduce the degree of edematous lung injury. This last finding further supports the hypothesis that glutathione depletion is an important 
mechanism by which chronic ethanol ingestion predisposes to acute lung injury. We used both SAM and NAC because experience in models of ethanol-induced hepatotoxicity has shown that this combination is much more effective at reducing liver injury than is NAC alone (36-38). Evidence suggests that mitochondrial and not cytosolic glutathione depletion is the major defect in ethanol-induced hepatocellular dysfunction $(36,37)$. Treatment with NAC alone does not increase hepatocyte mitochondrial glutathione levels in ethanol-fed rats (39), whereas treatment with SAM and NAC does $(36,37)$. The explanation for this is unknown but may relate to the specific transport of cytosolic glutathione into the mitochondria. Clearly, further studies will be necessary to define the optimal form and route of glutathione replacement therapy that can prevent and/or limit the cumulative effects of chronic alcohol abuse.

This last challenge is unfortunately consistent with the relatively disappointing results in several clinical trials of NAC therapy in patients with ARDS. In addition to augmenting glutathione synthesis, NAC has some oxygen radical scavenging properties on its own (13), and is well-known as a clinical antidote for acetaminophen overdose. In a trial of 66 patients with ARDS (40), NAC therapy was associated with a small increase in lung compliance compared with the control group but did not affect the survival rate. In another trial of 61 patients (41), NAC therapy was associated with improved oxygenation and decreased need for ventilatory support in patients with mild to moderate acute lung injury but again did not improve the survival rate. Finally, a study in 30 ARDS patients (42) showed that NAC therapy was associated with improvements in pulmonary hemodynamics and gas exchange. However, as noted above, NAC may not be an ideal agent because it may not increase mitochondrial glutathione levels, and indeed this may in part explain its relatively modest impact on a disease in which glutathione homeostasis appears to be important. In addition, one could predict that the chronic type II cell dysfunction caused by alcohol abuse would not be rapidly reversed with glutathione replacement, particularly during ARDS when additional type II cell damage has occurred already.

In summary, we determined that ethanol ingestion in rats decreased type II cell glutathione levels, impaired type II cell surfactant synthesis and viability in response to oxidative stress, and predisposed the lung to neutrophil-mediated acute edematous injury after endotoxemia. Although these findings suggest a potential mechanism by which chronic alcohol abuse can predispose patients to ARDS, further studies are needed to examine the precise mechanisms by which ethanol deranges type II cell glutathione homeostasis and cellular function. These observations also suggest that pharmacological replacement of glutathione may require some refinement but nevertheless has significant potential in limiting the development and/or severity of ARDS in selected at-risk patients.

\section{Acknowledgments}

The authors wish to thank Robert Raynor and Frank Harris for their technical support.

This work was supported by a grant from the National Heart, Lung, and Blood Institute (K-11HL-02690) and a National Research Grant from the American Lung Association. Dr. Holguin's research efforts were generously supported by the Department of Medicine at Emory University and its chairman, Juha P. Kokko, M.D., Ph.D.

\section{References}

1. Ward, P., K. Johnson, and G. Till. 1986. Animal models of oxidant lung injury. Respiration. 50(Suppl. 1):5-12.

2. Ashbaugh, D.G., D.B. Bigelow, T.L. Petty, and B.E. Levine. 1967. Acute respiratory distress in adults. Lancet. 12:319-323.

3. Sibblad, W.J., and C.M. Martin. 1993. The multiple organ dysfunction syndrome. In Pulmonary and Critical Care Medicine. R.C. Bone, editor. Mosby, St. Louis. 1-22.

4. Montgomery, A.B., M.A. Stager, C.J. Carrico, and L.D. Hudson. 1985 Causes of mortality in patients with adult respiratory distress syndrome. Am. Rev. Respir. Dis. 132:485-489.

5. Bone, R.C. 1991. Gram-negative sepsis: background, clinical features, and intervention. Chest. 100:802-808.

6. Bone, R.C. 1991. Sepsis, the sepsis syndrome, multi-organ failure: a plea for comparable definitions. Ann. Intern. Med. 114:332-333.

7. Pepe, P.E., R.T. Potkin, D.H. Reus, L.D. Hudson, and C.J. Carrico. 1982. Clinical predictors of the adult respiratory distress syndrome. Am. J. Surg. 144: 124-130.

8. Fowler, A.A., R.F. Hamman, J.T. Good, K.N. Benson, M. Baird, D.J. Eberle, T.L. Petty, and T.M. Hyers. 1988. Adult respiratory distress syndrome: risk with common predispositions. Ann. Intern. Med. 98:593-597.

9. Rivara, F.P., T.D. Koepsell, G.J. Jurkovich, and J.G. Gurney. 1993. The effect of acute alcohol intoxication and chronic alcohol abuse on outcome from trauma. JAMA (J. Am. Med. Assoc.). 270:51-56.

10. Moss, M., B. Bucher, F.A. Moore, E.E. Moore, and P.E. Parsons. 1996. The role of chronic alcohol abuse in the development of acute respiratory distress syndrome in adults. JAMA (J. Am. Med. Assoc.). 275:50-54.

11. Jewell, S.A., D. Di-Monte, A. Gentile, A. Guglielmi, E. Altomare, and O. Albano. 1986. Decreased hepatic glutathione in chronic alcoholic patients. $J$. Hepatol. 3:1-6.

12. Lieber, C.S. 1993. Biochemical factors in alcoholic liver disease. Sem. Liver Dis. 13:136-153.

13. Sala, R., E. Moriggi, G. Corvasce, and D. Morelli. 1993. Protection by $\mathrm{N}$-acetylcysteine against pulmonary endothelial cell damage induced by oxidant injury. Eur. Respir. J. 6:440-446.

14. Bunnell, E., and E.R. Pacht. 1993. Oxidized glutathione is increased in the alveolar fluid of patients with the adult respiratory distress syndrome. Am. Rev. Respir. Dis. 148:1174-1178.

15. Morris, P.E., and G.R. Bernard. 1994. Significance of glutathione in lung disease and implications for therapy. Am. J. Med. Sci. 307:119-127.

16. Adamson, I.Y.R., and D.H. Bowden. 1974. The type II cell as progenitor of alveolar epithelial regeneration. A cytodynamic study in mice after exposure to oxygen. Lab. Invest. 30:35-42.

17. Crim, C., and R.H. Simon. 1988. Effects of oxygen metabolites on rat alveolar type II cell viability and surfactant metabolism. Lab. Invest. 58:428-437.

18. Seeger, W., A. Gunther, H.D. Walmrath, F. Grimminger, and H.G. Lasch. 1993. Alveolar surfactant and adult respiratory distress syndrome. Pathogenetic role and therapeutic prospects. Clin. Invest. 71:177-190.

19. Gregory, T.J., W.J. Longmore, M.A. Moxley, J.A. Whitsett, C.R. Reed, A.A. Fowler, L.D. Hudson, R.J. Maunder, C. Crim, and T.M. Hyers. 1991. Surfactant chemical composition and biophysical activity in acute respiratory distress syndrome. J. Clin. Invest. 88:1976-1981.

20. Voelkel, N.F., J. Czartolomna, J. Simpson, and R.C. Murphy. 1992. FMLP causes eicosanoid-dependent vasoconstriction in lungs from endotoxinprimed rats. Am. Rev. Respir. Dis. 145:701-711.

21. Townsley, M.I., R.J. Korthuis, B. Rippe, J.C. Parker, and A.E. Taylor. 1986. Validation of double vascular occlusion method for Pc,i in lung and skeletal muscle. J. Appl. Physiol. 61:127-132.

22. Bradley, P.P., D.A. Priebat, R.D. Christensen, and G. Rothstein. 1982. Measurement of cutaneous inflammation: estimation of neutrophil content with an enzyme marker. J. Invest. Dermatol. 78:206-209.

23. Martin, J., and J.M. White. 1991. Fluorometric determination of oxidized and reduced glutathione in cells and tissues by high-performance liquid chromatography following derivatization with dansyl chloride. J. Chromatogr. 568:221-225.

24. Reed, D.J., J.R. Babson, P.W. Beatty, A.E. Brodie, W.W. Ellis, and D.W. Potter. 1980. High performance liquid chromatography analysis of nanomole levels of glutathione, glutathione disulfide and related thiols and disulfides. Anal. Biochem. 106:55-62.

25. Rennard, S.I., G. Basset, D. Lecossier, K.M. O’Donnell, P. Pinkston, P.G. Martin, and R.G. Crystal. 1986. Estimation of volume of epithelial lining fluid recovered by lavage using urea as marker of dilution. J. Appl. Physiol. 60: 532-538.

26. Dobbs, L.G., R. Gonzalez, and M.C. Williams. 1986. An improved method for isolating type II cells in high yield and purity. Am. Rev. Respir. Dis. 134:141-145.

27. Brown, L.A.S. 1991. Influence of streptozotocin-induced diabetes on adenylate cyclase activity in cultured type II pneumocytes. Am. J. Respir. Cell. Mol. Biol. 4:108-114.

28. Folch, J., M. Lees, and G.H. Sloane-Stanley. 1957. A simple method for the isolation and purification of total lipids from animal tissues. J. Biol. Chem. 
226:496-509

29. Tsai, M.Y., M. Cain, and M.W. Josephson. 1981. Improved thin layer chromatography of disaturated phosphatidylcholine in amniotic fluid. Clin. Chem. 27:239-242.

30. Barrios, V., M.N. Rodriguez-Sanchez, M. Hernandez, and E. Arilla. 1991. Maternal ethanol ingestion and somatostatin level and binding in developing rat brain. Am. J. Physiol. 261:E758-E763.

31. Floyd, E.A., A.K. Keaton, J.T. Clark, and H.K. Rucker. 1995. Chronic ethanol ingestion alters parameters of mid-latency auditory evoked potentials in male rats. Alcohol. 12:15-22.

32. Carreras, O., A.L. Vazquez, J.M. Rubio, M.J. Delgado, and M.L. Murillo. 1992. Effect of chronic ethanol on D-galactose absorption by the rat whole intestinal surface. Alcohol. 9:83-86.

33. Uysal, M., G. Aykac, N. Kocak-Toker, A. Sivas, S. Yalcin, and H. Oz. 1985. Lipid peroxidation in liver, plasma, and erythrocytes of rats chronically treated with ethanol. Biochem. Med. 34:370-372.

34. Kretzschmar, M., D. Reinhardt, J. Schlechtweg, G. Machnik, W. Klinger, and W. Schirmeister. 1992. Glutathione homeostasis in rats chronically treated with ethanol. Evidence for an increased hepatic GSH export in vivo. Exp. Toxicol. Pathol. 44:344-348.

35. Yang, C.M., and G.P. Carlson. 1990. Influence of ethanol on glutathione- $S$-transferase activity and glutathione content in the isolated perfused rabbit lung. Toxicology. 62:249-263.
36. Garcia-Ruiz, C., A. Morales, A. Colell, A. Ballesta, J. Rodes, N. Kaplowitz, and J.C. Fernandez-Checa. 1995. Feeding $S$-adenosyl-L-methionine attenuates both ethanol-induced depletion of mitochondrial glutathione and mitochondrial dysfunction in periportal and perivenous rat hepatocytes. Hepatology. 21:207-214.

37. Fernandez-Checa, J.C., C. Garcia-Ruiz, M. Ookhtens, and N. Kaplowitz. 1991. Impaired uptake of glutathione by hepatic mitochondria from chronic ethanol-fed rats. Tracer kinetic studies in vitro and in vivo and susceptibility to oxidant stress. J. Clin. Invest. 87:397-405.

38. Lieber, C.S., A. Casini, and L.M. DeCarli. 1990. S-adenosyl-L-methionine attenuates alcohol-induced liver injury in the baboon. Hepatology. 11:165-172.

39. Fernandez-Checa, J.C., T. Hirano, H. Tsukamoto, and N. Kaplowitz 1993. Mitochondrial glutathione depletion in alcoholic liver disease. Alcohol. 10:469-475.

40. Jepsen, S., P. Herlevsen, P. Knudsen, M.I. Bud, and N. Klausen. 1992. Antioxidant treatment with $\mathrm{N}$-acetylcysteine during adult respiratory distress syndrome: a prospective, randomized, placebo-controlled study. Crit. Care Med. 20:918-923.

41. Suter, P.M., G. Domenighetti, M. Schaller, M. Laverriere, R. Ritz, and C. Perret. 1994. $N$-Acetylcysteine enhances recovery from acute lung injury in man. Chest. 105:190-194.

42. Bernard, G.R. 1991. N-Acetylcysteine in experimental and clinical acute lung injury. Am. J. Med. 91(Suppl. 3C):54S-59S. 